\title{
HLA-C incompatibilities in allogeneic unrelated hematopoietic stem cell transplantation
}

\author{
Jean-Marie Tiercy * \\ Transplantation Immunology Unit, National Reference Laboratory for Histocompatibility, Department of Genetics and Laboratory Medicine, University Hospital of \\ Geneva, University of Geneva, Geneva, Switzerland
}

\section{Edited by:}

Effie Wang Petersdorf, University of Washington School of Medicine, USA

\section{Reviewed by:}

Reem Al-Daccak, Institut National de Santé et de Recherche Médical,

France

Eric Spierings, University Medical

Center Utrecht, Netherlands

\section{*Correspondence:}

Jean-Marie Tiercy, Transplantation Immunology Unit, National Reference Laboratory for Histocompatibility, Department of Genetics and Laboratory Medicine, University Hospital of Geneva, University of Geneva, 4 rue Gabrielle-Perret-Gentil, 1211 Geneva 14, Switzerland e-mail: jean-marie.tiercy@unige.ch
An increasingly larger fraction of patients with hematological diseases are treated by hematopoietic stem cells transplantation (HSCT) from HLA matched unrelated donors. Polymorphisms of HLA genes represent a major barrier to HSCT because HLA-A, - B, -C and DRB1 incompatibilities confer a higher risk of acute graft-versus-host disease (aGVHD) and mortality. Although >22 million volunteer HLA-typed donors are available worldwide, still a significant number of patients do not find a highly matched HSC donor. Because of the large haplotypic diversity in HLA-B-C associations, incompatibilities occur most frequently at $\mathrm{HLA}-\mathrm{C}$, so that unrelated donors with a single HLA-C mismatch often represent the only possible choice. The ratio of HLA-C-mismatched HSCT over the total number of transplants varies from 15 to $30 \%$, as determined in 12 multicenter studies. Six multicenter studies involving $>1800$ patients have reported a $21-43 \%$ increase in mortality risk. By using in vitro cellular assays, a large heterogeneity in T-cell allorecognition has been observed. Yet the permissiveness of individual HLA-C mismatches remains poorly defined. It could be linked to the position and nature of the mismatched residues on HLA-C molecules, but also to variability in the expression levels of the mismatched alleles. The permissive $C * 03: 03-03: 04$ mismatch is characterized by full compatibility at residues $9,97,99,116,152,156$, and 163 reported to be key positions influencing T-cell allorecognition. With a single difference among these seven key residues the $C^{*}$ 07:01-07:02 mismatch might also be considered by analogy as permissive. High variability of HLA-C expression as determined by quantitative RT-PCR has been observed within individual allotypes and shows some correlation with A-B-C-DRB1 haplotypes. Thus in addition to the position of mismatched amino acid residues, expression level of patient's mismatched HLA-C allotype might influence T-cell allorecognition, with patients low expression-C alleles representing possible permissive mismatches.

Keywords: HLA-C polymorphism, stem cell transplantation, incompatibilities, permissive mismatches, clinical outcome, HLA-C expression levels

\section{INTRODUCTION}

HLA compatibility is a crucial parameter that influences the clinical outcome of hematopoietic stem cells transplantation (HSCT). Whereas it is technically simple to assess genotypic HLA compatibility in a related HSCT setting, the situation becomes more complex for unrelated donor selection. Here the developments in HLA typing technology have significantly contributed to improve the efficiency of unrelated HSC donor searches, resulting in a better recipient-donor HLA matching and a better prognostic for clinical outcome. In most transplant centers matching at HLA-A, -B, -C, DRB1, and DQB1 loci, a so-called 10/10 match, is the gold standard for unrelated donor selections (1-3). Although single DQB1 mismatches appear to be better tolerated than mismatches at other loci, they have an additive effect to A, B, C, DRB1 loci (1-4).

Historically, the recognition of HLA-C mismatches as bona fide transplantation antigens occurred a few years after the demonstration of the relevance of HLA-A, -B, DRB1 mismatches (5-7), because of the later developments in DNA-based analysis of HLA$\mathrm{C}$ allelic polymorphism. Among HLA class I incompatibilities, a higher frequency of HLA-C compared to HLA-A, -B disparities has been disclosed, thus conferring a higher statistical power to the analysis of its role, possibly contributing to overestimate the impact of C-mismatches relative to disparities at other HLA loci. In any case large evidence points now to the clinical relevance of including HLA-C matching in the donor search algorithm.

The key role of HLA-C molecules as ligands of killer immunoglobulin-like receptors (KIRs) adds further complexity to a fair evaluation of the impact of HLA-C incompatibilities in HSCT. A large body of data pointing to the crucial role of HLAKIR interactions in controlling the antileukemic activity of donor NK cells have been extensively reviewed elsewhere (8-10) and will therefore not be addressed here.

\section{OCCURRENCE AND CLINICAL RELEVANCE OF HLA-C INCOMPATIBILITIES}

Prospective and/or retrospective HLA typing of HSCT donor/recipient pairs showed that HLA-C mismatches represent $40-50 \%$ of all HLA class I and II incompatibilities (DPB1 not 
being considered) (Table 1). As determined in 11 different cohorts, a donor with a single HLA-C disparity had been selected in $13-31 \%$ of all transplants (Table 1). About $80 \%$ of HLA-C disparities concerned antigen mismatches (11-13). Thus HLA-C is by far the most frequent HLA mismatch, whereas the lowest rate of mismatches is found at locus DRB1. This probably reflects a more stringent priority given to DRB1 matching, less advanced technology for HLA-A, -B high resolution typing in clinical laboratories during the years 1990-2000, and more recent application of HLA-C prospective typing in the donor search algorithms (14).

Ten clinical studies including $>100$ patients have specifically addressed the impact of HLA-C allele or antigen disparities and they all report a deleterious role of C-mismatches. As summarized in Table 2, six studies report a $20-100 \%$ increased risk of acute GVHD $(11,13,15,16,21,24)$. Out of the 10 studies analyzing overall survival, 8 report a $21-94 \%$ statistically significant increased mortality risk (11-13,21,24-26). Interestingly, the study that did not observe any impact of C-mismatches (assigned by retrospective typing) on survival concerns HSCT performed in 1993-1998 by the Japanese Marrow Donor Program (JMDP) (15). When JMDP patients transplanted in a later period (2000-2009) were analyzed the deleterious impact of C-mismatches became significant (23).

The evaluation of the relative importance of HLA-C mismatches may be influenced by differences in the frequencies of individual mismatches in different populations. For example, the $C^{\star}$ 03:03-03:04 mismatch accounted for $68.7 \%$ of $\mathrm{C}$ allele

Table 1 | Rate of HLA-C mismatches (MM) in different unrelated HSCT cohorts.

\begin{tabular}{llll}
\hline Reference & $\begin{array}{l}\text { C-MM/total nb } \\
\text { MM (\%) }\end{array}$ & $\begin{array}{l}\text { C-MM/total nb } \\
\text { pat (\%) }\end{array}$ & YearTXc \\
\hline$(15)$ & $156 / 412(37.8)$ & $156 / 973(16)$ & $1993-1998$ \\
$(16)$ & - & $\begin{array}{l}\text { 749/1874 (40, incl. } \\
\text { multiple MM) }\end{array}$ & $1988-1996$ \\
& & $253 / 948(26.7$, & $1985-2003$ \\
$(17)$ & $85 / 248$ single & incl. multiple MM) & \\
& MM (34.3) & $34 / 144(23.6)$ & $1994-2003$ \\
$(18)$ & $34 / 74(45.9)$ & $29 / 214(13.6)$ & $1990-2003$ \\
$(19)$ & $29 / 69(42)$ & $91 / 334(27)$ & $1993-2003$ \\
$(20)$ & $91 / 187(48.6)$ & $478 / 2825(16.9)$ & $1988-2003$ \\
$(21)$ & $478 / 985(48.5)$ & $419 / 1361(31)$ & \\
$(22)$ & - & $250 / 1741(14.4)$ & $1999-2006$ \\
$(11)$ & $250 / 498(50.2)^{d}$ & $634 / 2646(24)$ & $1997-2010$ \\
$(12)$ & $634 / 1524(41.6)$ & $524 / 3003(17.4)$ & $1993-2009$ \\
$(23)$ & $524 / 1037(50.5)$ & - & $1988-2009$ \\
$(24)$ & $1016 / 2031(50)^{d}$ & $895 / 6633(13.5)$ & $1988-2009$ \\
$(13)$ & $895 / 1854(48.3)^{d}$ & &
\end{tabular}

${ }^{a}$ Number (nb) of patient/donor combinations with a single HLA-C mismatch (MM)/total nb of mismatches for HLA-A, -B, -C, DRB1, DQB1 loci.

${ }^{b}$ Number (nb) of patient/donor combinations with a HLA-C mismatch (MM)/total nb of patients.

'Time-frame of the HSCT included in the study (TX: transplantation).

${ }^{d}$ Only 7/8 matched donors with single class I MM were considered. disparities in the recent CIBMTR study (13), but only $44.4 \%$ of the allele disparities detected in the JMDP study (28).

Furthermore, the relevance HLA-C allele versus antigen mismatches $(11,13,21)$ may be biased by the nature of individual mismatches. Very few data are available concerning the relative frequencies of individual C-mismatches $(13,28,29)$. Because of the very different HLA haplotypes in the Japanese population a significant fraction of the C-mismatches will not be encountered in patients of European ancestry. For example, allele mismatches within the $\mathrm{C}^{\star} 07$ allotype occur more frequently in patients cohorts of European ancestry, when compared to the JMDP study (28). As determined in the IHWS HSCT cohort $C^{\star} 03: 03-03: 04$ mismatches accounted for 21/257 (8.2\%) and 12/82 (14.6\%) single (antigen and allele) HLA-C disparities, in JMDP and, respectively, non-JMDP patients (28). Of 257 HLA-C mismatched pairs identified in the non-JMDP patients, $172(70 \%)$ were not found in the JMDP patient/donor pairs. Therefore the nature of individual mismatches strikingly differs in European and Asian populations.

\section{RELATIVE IMPORTANCE OF INDIVIDUAL HLA-C MISMATCHES}

In a first attempt from the JMDP to disclose individual HLA$\mathrm{C}$ mismatches with higher clinical relevance, seven HLA-C allele mismatched combinations were reported to confer a higher risk of acute GVHD (29). Four amino acid residues at positions 9, 99, 116, and 156 of HLA-C molecules were significantly associated with acute graft-versus-host disease (aGVHD). A subsequent JMDP study showed that four specific HLA-C mismatches, $C^{\star} 01: 02-$ 14:02, $C^{\star} 08: 01-01: 02, C^{\star} 14: 02-03: 04$, and $C^{\star} 15: 02-14: 02$ were associated with a lower risk of relapse (30), the latter being among the ones reported previously to confer a higher aGVHD risk (29).

New insights on the role of specific residues of HLA molecules in peptide-binding and TCR recognition (31) allowed a much better understanding of the T-cell alloreactive response to mismatched HLA antigens. The concept that specific residues could be essential in allorecognition led to a few clinical studies aimed at demonstrating the predominant role of discrete parts of the incompatible HLA molecules in clinical outcome $(24,32,33)$.

Using a random forest statistical analysis 13 amino acid (aa) substitutions in the HLA class I peptide-binding pocket have been reported to be associated with increased mortality at day 100 in low/intermediate risk patients transplanted with HSC from a single HLA class I mismatched donor, with positions 9, 99, 116, and 156 being the most clinically relevant (33). HLA-C mismatch at position 99 was reported to be associated with increased TRM and a C-mismatch at position 116 with increased risk of acute GVHD.

When comparing individual C-mismatches at seven key residues in the peptide-binding site (PBS) that have been reported to be non-permissive substitutions marked differences are observed (Table 3). Strikingly, two of the most frequent mismatches exhibit no $\left(C^{\star} 03: 03-03: 04\right)$ or only one $\left(C^{\star} 07: 01-07: 02\right)$ amino acid (aa) difference at positions 9, 97, 99, 116, 152, 156, and 163 , whereas all other common mismatches include a substitution at 3-6 positions. Whether this difference may allow classifying HLA-C incompatibilities as permissive/non-permissive, remains to be confirmed. It is however relevant to note that the $C^{\star}$ 03:03-03:04 mismatch did result in a negative or weakly 
Table 2 | Hazard ratios for two outcomes in nine HSCT cohorts with single HLA-C mismatches.

\begin{tabular}{|c|c|c|c|c|c|c|}
\hline Reference & Nb pat & TCD/RIC & Year TX & $\begin{array}{l}\mathrm{Nb} \\
\mathrm{C}-\mathrm{MM}\end{array}$ & $\begin{array}{l}\text { aGVHDa } \\
\text { HR }(95 \% \mathrm{CI})\end{array}$ & $\begin{array}{l}\text { OS } \\
\text { HR (95\% Cl) }\end{array}$ \\
\hline (15) & 1288 & No TCD & 1993-1998 & $156 / 272^{b}$ & $1.85(1.42-2.41) p<0.001$ & No impact \\
\hline \multirow[t]{2}{*}{$(17)$} & 948 & No TCD & 1985-2003 & $24^{c}$ & - & $3.18(1.74-5.82)$ \\
\hline & & & & 61 & - & $1.32(0.95-1.84)$ \\
\hline$(16)$ & 1874 & - & 1988-1996 & 749 & $1.19(1-1.41) p=0.05$ & $1.21(1.06-1.38) p=0.005$ \\
\hline (25) & 114 (CML) & $32 \% \mathrm{TCD}$ & 1988-1999 & 24 & - & $1.94(1.0-3.9) p=0.06$ \\
\hline$(26)$ & 111 & $100 \%$ RIC & 2000-2004 & 33 & - & $1.85 p=0.04$ \\
\hline \multirow[t]{2}{*}{$(21)$} & 2825 & $36 \%$ TCD & 1988-2003 & 382 & $1.6(1.33-1.93) p<0.001$ & $1.22(1.06-1.39) p=0.004$ \\
\hline & & No RIC & & & & \\
\hline \multirow[t]{2}{*}{$(11)$} & 1933 & $35 \% \mathrm{RIC}$ & 1992-2006 & $168 / 189^{d}$ & $1.98(1.5-2.62) p<0.001$ & $1.41(1.16-1.70) p=0.005$ \\
\hline & & No TCD & & & Grade III-IV & \\
\hline \multirow[t]{2}{*}{$(12)$} & 3035 & NoTCD & 1997-2010 & 620 & - & $1.35(1.17-1.56) p<0.001$ \\
\hline & & $36 \% \mathrm{RIC}$ & & & & \\
\hline \multirow[t]{3}{*}{ (23) } & 751 & No TCD/RIC & 1993-1999 & 124 & $2.02(1.27-3.20) p=0.0029$ & $0.96(0.73-1.26) p=0.77$ \\
\hline & 2252 & & 2000-2009 & 386 & $1.51(1.12-2.02) p=0.0067$ & $1.35(1.15-1.59) p=0.0003$ \\
\hline & & & & & Grade III-IV & \\
\hline (13) & 6633 & $22 \% \mathrm{RIC}$ & 1988-2009 & $700^{e}$ & $1.72(1.11-2.69) p=0.02$ & $1.43(1.06-1.92) p=0.02$ \\
\hline
\end{tabular}

${ }^{a}$ Grade II-IV except for Ref. (16, 23).

${ }^{b} \mathrm{C}$-mismatches and aGVHD risk: 156 single MM, 272 multiple MM.

'Single C-MM, low risk disease: 24 patients, high/intermediate risk disease: 61 patients.

${ }^{d}$ Antigen MM only (64 allele MM have no impact on GVHD/OS), 168 C-MM (aGVHD), 189 C-MM (OS).

eAntigen MM.

$T C D$, T-cell depletion; RIC, reduced intensity conditioning.

Table 3 | Substitutions in the peptide-binding site (PBS) associated with outcome $(3,24,32)$ in 13 frequent HLA-C mismatches as reported in Ref. (28).

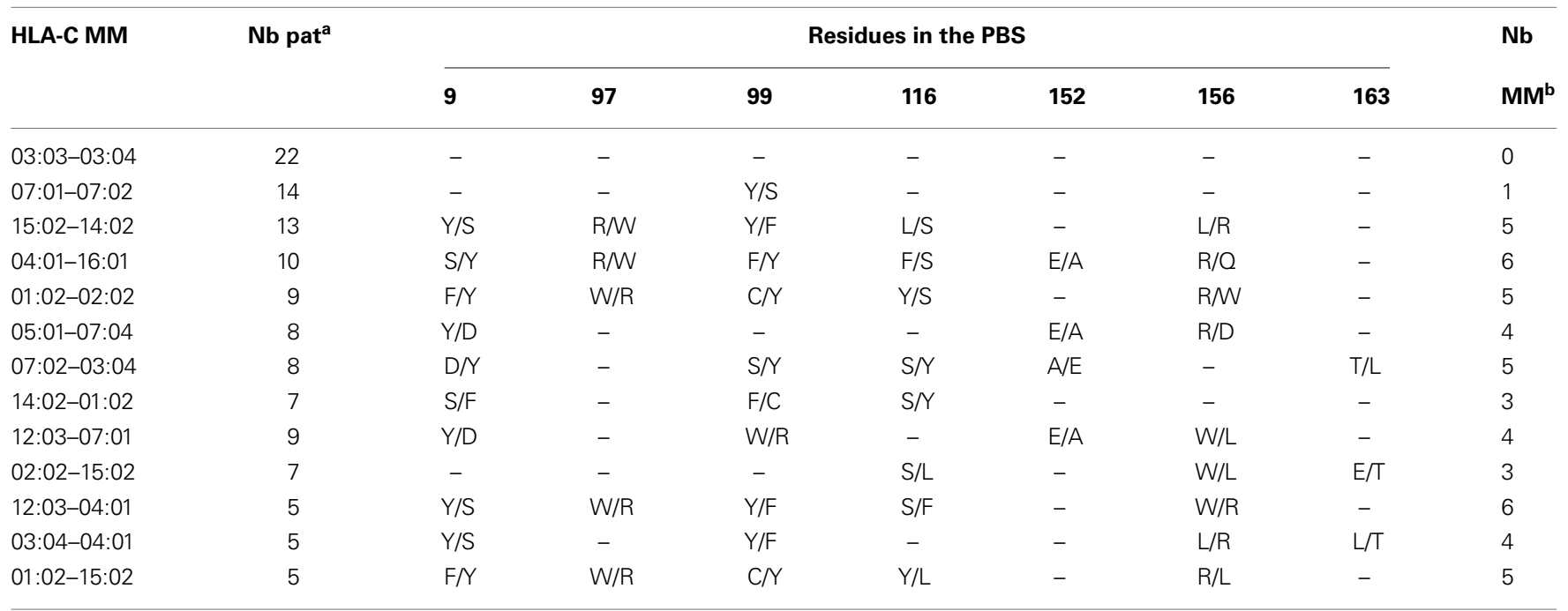

${ }^{a}$ Number of patient/donor pairs.

${ }^{b}$ Number of mismatched residues in the PBS (out of the seven key amino acids reported to be associated with outcome).

positive CTL-precursor frequency (CTLpf) analysis (34, 35), and was therefore considered as a potential permissive mismatch. This is supported by a recent large scale study showing that $7 / 8$ matched HSCT patients with a single $C^{\star}$ 03:03-03:04 mismatch had the same outcome as compared to $8 / 8$ matched patients (13). On the other hand, two of the most frequent C-disparities differed by $5-$ 6 key residues in the peptide-binding pocket: the $C^{\star} 15: 02-14: 02$ mismatch in B51-positive patients and the $C^{\star} 04: 01-12: 03$ mismatch in B35-positive patients. It is tempting to suggest that such mismatches could be considered as non-permissive. 


\section{RECOGNITION OF HLA-C INCOMPATIBILITIES BY ALLOREACTIVE T CELLS}

In a first small scale study combining DNA typing and in vitro cellular assays such as the CTLpf analysis, the results suggested that HLA-C incompatibilities that were negative in an in vitro CTLpf assay may be of lower clinical relevance (5). It is well documented that single HLA class I allele mismatches, including HLA-C disparities, are efficiently recognized by CTLs (7, 35-42).

Based on CTLpf analysis of donor/recipient pairs with a single HLA-C incompatibility, alloreactivity was reported to be influenced by the number and position of the mismatched residues in the PBS (39). Negative CTLpf assays occurred more frequently in pairs with $>9$ aa differences compared to pairs with $0-5$ aa differences in the $\alpha$-helices and $\beta$-sheet. A model to predict cytotoxic T-cell alloreactivity was based on an amino acid mismatch score depending on the position and physicochemical properties of the mismatched residues (40). After testing the model on 1719/10 and 168 10/10 matched HSCT patients, these authors found out that the aa mismatch score did not predict clinical outcome (41).

Infection- and vaccine-induced memory $\mathrm{T}$ cells have a high cross-reactive potential against allo-MHC molecules (43). Substitutions at key residues in the PBS (Table 3 ) are expected to modify the endogenous peptide repertoire bound to allo-HLA molecules, thereby increasing the cross-reactive potential of virus-specific memory T cells. Possibly multiple substitutions of key residues in the PBS (e.g., $C^{\star 03: 04-07: 02) ~ m a y ~ i n c r e a s e ~ t h e ~ n u m b e r ~ o f ~}$ cognate ligands recognized by alloreactive T-cells (structural mimicry), as compared to mismatches with a single substitution such as $C^{\star}$ 07:01-07:02. Accurate modeling of peptide-HLA interactions (44) allowing to point to high risk non-permissive substitutions should contribute to a better evaluation of the permissiveness of HLA class I mismatched residues.

\section{HLA-C EXPRESSION LEVEL AND ALLOREACTIVITY}

In the last couple of years, several studies have pointed to variability in HLA-C expression levels, as analyzed by RT-PCR and by DT9 antibody binding in heterozygous individuals. Such variability was shown to correlate with the antiviral response in $\mathrm{HIV}+$ patients $(45,46)$. The association with HIV disease outcome was originally reported to be linked to a dimorphism at $-35 \mathrm{~kb}$ upstream the HLA-C gene $(27,45)$. Subsequently, HLA-C expression was reported to be determined by a microRNA binding site dimorphism (263 indel) in the $3^{\prime} \mathrm{UT}$ region of HLA-C (47), and most recently by a MIR148A polymorphism affecting the microRNA miR-148a own expression and consequently the level of HLA$\mathrm{C}$ expression in individuals carrying an intact miR-148a binding site (48).

Although the determination of HLA-C by DT9 antibody staining has the advantage to reflect bona fide cell surface expression it does not allow to dissect haplotype-dependant expression levels because the large majority of individuals are heterozygous. Even homozygous donors might show different HLA-C expressions levels that would depend on the extended ABDR haplotypes. This may account for apparent differences in expression levels reported previously. For example, HLA-C ${ }^{\star}$ 07:02-positive (heterozygous) individuals were first classified among those with high expression allotypes (45), whereas it is found among the low expression allotypes in a study on African-American patients (46). Apparent inconsistencies are also noted when HLA-C allotypes were classified with high or low expression as based on DT9 antibody binding or on polymorphism in the $3^{\prime} \mathrm{UTR}$ miR-148 binding site. For example $C^{\star} 01: 02$ and $C^{\star} 04: 01$ are classified as low expression alleles based on the $3^{\prime}$ UTR miR-148 binding site, but as high expression alleles based on DT9 binding. $C^{\star} 05: 01$ is classified as a high expression allele based on $3^{\prime}$ UTR 263 indel, but is reported as low/intermediate based on DT9 binding. We have recently reported some evidence that HLA-C alleles can not be simply classified as high/low expression alleles, because significant interindividual variability was disclosed, at least for the $C^{\star} 03: 04$, $C^{\star} 04: 01, C^{\star} 05: 01$, or $C^{\star} 06: 02$ allotypes (49). Relevant correlation was found between HLA-C mRNA expression levels and the extended HLA-A, -B, DRB1 haplotypes. Under the hypothesis that differences in the level of expression might directly influence the CTL response, a simple test for quantifying allele-specific anti-HLA-C alloreactive T-cell responses or, indirectly, HLA-C recipient allotype expression levels, would help in donor selection and risk assessment before HSCT. Because HLA-C expression levels may impact both positive and negative thymic selection in the donor it is difficult to predict how this would translate in the donor $\mathrm{T}$ cell-mediated alloresponse against mismatched HLA-C antigens.

In summary, clinical studies point to a negative impact of single HLA-C mismatches in unrelated HSCT, with a $21-43 \%$ increased mortality risk. In the vast majority of the transplant centers unrelated donor search algorithms now take HLA-C compatibility into account. However, the diversity of HLA-B-C associations in specific haplotypes results in a rather high rate of HLA-C mismatches. The strength of the immune responses to HLA-C disparities may vary in different patient/donor combinations. HLA-C allorecognition will be impacted by the position of the mismatched residues on the HLA molecule, by the level of expression of the targeted mismatched allotype, and by the T-cell repertoire of the donor, which is modulated by the infectious history of each individual. Possible permissive mismatches may be assigned when no or very few substitutions occur at the key positions 9, 97, 99, 116, 152, 156, and 163 in the peptide-binding pocket, or in cases of low expression mismatched alleles, such as $C^{\star}$ 07:01/02 alleles. By analogy to findings concerning HLA-B incompatibilities (50), it may be anticipated that HLA-C disparities that involve residue(s) in the $\alpha 3$-domain (such as the $C^{\star 02: 02-02: 29 ~ m i s m a t c h) ~ m a y ~ b e ~ c o n-~}$ sidered as permissive mismatches. This remains however to be demonstrated by functional in vitro assays, until clinical studies become large enough to provide sufficient statistical power for an analysis of $\alpha 3$-domain disparities. A better definition of such mismatches is required to increase the pool of acceptable donors, particularly for patients with rare HLA-B-C haplotypes.

\section{ACKNOWLEDGMENTS}

I thank the LNRH team for their strong technical support and Dr. F. Bettens for stimulating discussions. The excellent collaboration with Pr. Y. Chalandon, Pr. J. Passweg, PD Dr. U. Schanz, and PD Dr. T. Güngör, heads of the four Swiss allogenic stem cell transplant centers, and with Dr. Nicoloso from the Swiss Blood Stem Cells (SBSC) registry is acknowledged. This work is supported by grant No.310030_146306/1 from the Swiss National Science Foundation and by a grant from the IRGHET Foundation. 


\section{REFERENCES}

1. Petersdorf EW. Optimal HLA matching in hematopoietic cell transplantation. Curr Opin Immunol (2008) 20(5):588-93. doi:10.1016/j.coi.2008.06.014

2. Shaw BE, Arguello R, Garcia-Sepulveda CA, Madrigal JA. The impact of HLA genotyping on survival following unrelated donor haematopoietic stem cell transplantation. Br J Haematol (2010) 150(3):251-8. doi:10.1111/j.1365-2141. 2010.08224.x

3. Tiercy JM. Unrelated hematopoietic stem cell donor matching probability and search algorithm. Bone Marrow Res (2012) 2012:695018. doi:10.1155/2012/ 695018

4. Horan J, Wang T, Haagenson M, Spellman SR, Dehn J, Eapen M, et al. Evaluation of HLA matching in unrelated hematopoietic stem cell transplantation for nonmalignant disorders. Blood (2012) 120(14):2918-24. doi:10.1182/blood-201203-417758

5. Speiser DE, Tiercy JM, Rufer N, Grundschober C, Gratwohl A, Chapuis B, et al. High resolution HLA matching associated with decreased mortality after unrelated bone marrow transplantation. Blood (1996) 87(10):4455-62.

6. Petersdorf EW, Longton GM, Anasetti C, Mickelson EM, McKinney SK, Smith AG, et al. Association of HLA-C disparity with graft failure after marrow transplantation from unrelated donors. Blood (1997) 89(5):1818-23.

7. Scott I, O'Shea J, Bunce M, Tiercy JM, Arguello JR, Firman H, et al. Molecular typing shows a high level of HLA class I incompatibility in serologically well matched donor/patient pairs: implications for unrelated bone marrow donor selection. Blood (1998) 92(12):4864-71.

8. Velardi A, Ruggeri L, Mancusi A. Killer-cell immunoglobulin-like receptors reactivity and outcome of stem cell transplant. Curr Opin Hematol (2012) 19(4):319-23. doi:10.1097/MOH.0b013e32835423c3

9. Falco M, Moretta L, Moretta A, Bottino C. KIR and KIR ligand polymorphism: a new area for clinical applications? Tissue Antigens (2013) 82(6):363-73. doi: $10.1111 / \tan .12262$

10. Babor F, Fischer JC, Uhrberg M. The role of KIR genes and ligands in leukemia surveillance. Front Immunol (2013) 4:27. doi:10.3389/fimmu.2013.00027

11. Woolfrey A, Klein JP, Haagenson M, Spellman S, Petersdorf E, Oudshoorn M, et al. HLA-C antigen mismatch is associated with worse outcome in unrelated donor peripheral blood stem cell transplantation. Biol Blood Marrow Transplant (2011) 17(6):885-92. doi:10.1016/j.bbmt.2010.09.012

12. Furst D, Muller C, Vucinic V, Bunjes D, Herr W, Gramatzki M, et al. Highresolution HLA matching in hematopoietic stem cell transplantation: a retrospective collaborative analysis. Blood (2013) 122(18):3220-9. doi:10.1182/ blood-2013-02-482547

13. Fernandez-Vina MA, Wang T, Lee SJ, Haagenson M, Aljurf M, Askar M, et al. Identification of a permissible HLA mismatch in hematopoietic stem cell transplantation. Blood (2014) 123(8):1270-8. doi:10.1182/blood-2013-10532671

14. Ottinger HD, Albert E, Arnold R, Beelen DW, Blasczyk R, Bunjes D, et al. German consensus on immunogenetic donor search for transplantation of allogeneic bone marrow and peripheral blood stem cells. Bone Marrow Transplant (1997) 20(2):101-5. doi:10.1038/sj.bmt.1700851

15. Morishima Y, Sasazuki T, Inoko H, Juji T, Akaza T, Yamamoto K, et al. The clinical significance of human leukocyte antigen (HLA) allele compatibility in patients receiving a marrow transplant from serologically HLA-A, HLAB, and HLA-DR matched unrelated donors. Blood (2002) 99(11):4200-6. doi:10.1182/blood.V99.11.4200

16. Flomenberg N, Baxter-Lowe LA, Confer D, Fernandez-Vina M, Filipovich A, Horowitz M, et al. Impact of HLA class I and class II high-resolution matching on outcomes of unrelated donor bone marrow transplantation: HLA-C mismatching is associated with a strong adverse effect on transplantation outcome. Blood (2004) 104(7):1923-30. doi:10.1182/blood-2004-03-0803

17. Petersdorf EW, Anasetti C, Martin PJ, Gooley T, Radich J, Malkki M, et al. Limits of HLA mismatching in unrelated hematopoietic cell transplantation. Blood (2004) 104(9):2976-80. doi:10.1182/blood-2004-04-1674

18. Greinix HT, Fae I, Schneider B, Rosenmayr A, Mitterschiffthaler A, Pelzmann $B$, et al. Impact of HLA class I high-resolution mismatches on chronic graftversus-host disease and survival of patients given hematopoietic stem cell grafts from unrelated donors. Bone Marrow Transplant (2005) 35(1):57-62. doi:10.1038/sj.bmt.1704741

19. Chalandon Y, Tiercy JM, Schanz U, Gungor T, Seger R, Halter J, et al. Impact of high-resolution matching in allogeneic unrelated donor stem cell transplantation in Switzerland. Bone Marrow Transplant (2006) 37(10):909-16. doi:10.1038/sj.bmt.1705353

20. Loiseau P, Busson M, Balere ML, Dormoy A, Bignon JD, Gagne K, et al. HLA Association with hematopoietic stem cell transplantation outcome: the number of mismatches at HLA-A, -B, -C, -DRB1, or -DQB1 is strongly associated with overall survival. Biol Blood Marrow Transplant (2007) 13(8):965-74. doi:10.1016/j.bbmt.2007.04.010

21. Lee SJ, Klein J, Haagenson M, Baxter-Lowe LA, Confer DL, Eapen M, et al. High-resolution donor-recipient HLA matching contributes to the success of unrelated donor marrow transplantation. Blood (2007) 110(13):4576-83. doi:10.1182/blood-2007-06-097386

22. Hurley CK, Fernandez-Vina M, Hildebrand WH, Noreen HJ, Trachtenberg E, Williams TM, et al. A high degree of HLA disparity arises from limited allelic diversity: analysis of 1775 unrelated bone marrow transplant donorrecipient pairs. Hum Immunol (2007) 68(1):30-40. doi:10.1016/j.humimm. 2006.09.004

23. Kanda Y, Kanda J, Atsuta Y, Maeda Y, Ichinohe T, Ohashi K, et al. Impact of a single human leucocyte antigen (HLA) allele mismatch on the outcome of unrelated bone marrow transplantation over two time periods. A retrospective analysis of 3003 patients from the HLA working group of the Japan society for blood and marrow transplantation. Br J Haematol (2013) 161(4):566-77. doi:10.1111/bjh.12279

24. Pidala J, Wang T, Haagenson M, Spellman SR, Askar M, Battiwalla M, et al. Amino acid substitution at peptide-binding pockets of HLA class I molecules increases risk of severe acute GVHD and mortality. Blood (2013) 122(22):3651-8. doi:10.1182/blood-2013-05-501510

25. Tiercy JM, Passweg J, van Biezen A, Zander A, Kroger N, Gratwohl A, et al. Isolated HLA-C mismatches in unrelated donor transplantation for CML. Bone Marrow Transplant (2004) 34(3):249-55. doi:10.1038/sj.bmt.1704569

26. Ho VT, Kim HT, Liney D, Milford E, Gribben J, Cutler C, et al. HLA-C mismatch is associated with inferior survival after unrelated donor nonmyeloablative hematopoietic stem cell transplantation. Bone Marrow Transplant (2006) 37(9):845-50. doi:10.1038/sj.bmt.1705315

27. Fellay J, Shianna KV, Ge D, Colombo S, Ledergerber B, Weale M, et al. A wholegenome association study of major determinants for host control of HIV-1. Science (2007) 317(5840):944-7. doi:10.1126/science.1143767

28. Petersdorf E. 13th IHWS transplantation of hematopoietic stem cells joint report. K2. Impact of donor-recipient HLA matching on survival after myeloablative hematopoietic cell transplantation from unrelated donors. In: Hansen JA, Dupont B editors. Immunobiology of the Human MHC. (Vol. I), Seattle: IHWG Press (2006). p. 1336-47.

29. Kawase T, Morishima Y, Matsuo K, Kashiwase K, Inoko H, Saji H, et al. Highrisk HLA allele mismatch combinations responsible for severe acute graftversus-host disease and implication for its molecular mechanism. Blood (2007) 110(7):2235-41. doi:10.1182/blood-2007-02-072405

30. Kawase T, Matsuo K, Kashiwase K, Inoko H, Saji H, Ogawa S, et al. HLA mismatch combinations associated with decreased risk of relapse: implications for the molecular mechanism. Blood (2009) 113(12):2851-8. doi:10.1182/blood2008-08-171934

31. Archbold JK, Macdonald WA, Burrows SR, Rossjohn J, McCluskey J. T-cell allorecognition: a case of mistaken identity or deja vu? Trends Immunol (2008) 29(5):220-6. doi:10.1016/j.it.2008.02.005

32. Ferrara GB, Bacigalupo A, Lamparelli T, Lanino E, Delfino L, Morabito A, et al. Bone marrow transplantation from unrelated donors: the impact of mismatches with substitutions at position 116 of the human leukocyte antigen class I heavy chain. Blood (2001) 98(10):3150-5. doi:10.1182/blood.V98.10.3150

33. Marino SR, Lin S, Maiers M, Haagenson M, Spellman S, Klein JP, et al. Identification by random forest method of HLA class I amino acid substitutions associated with lower survival at day 100 in unrelated donor hematopoietic cell transplantation. Bone Marrow Transplant (2012) 47(2):217-26. doi:10.1038/ bmt.2011.56

34. Roosnek E, Tiercy JM. Search for an unrelated HLA-compatible stem cell donor. Curr Opin Hematol (1999) 6(6):365-70. doi:10.1097/00062752-19991100000002

35. Oudshoorn M, Doxiadis II, van den Berg-Loonen PM, Voorter CE, Verduyn W, Claas FH. Functional versus structural matching: can the CTLp test be replaced by HLA allele typing? Hum Immunol (2002) 63(3):176-84. doi:10.1016/S0198-8859(01)00384-6 
36. Rufer N, Tiercy JM, Breur-Vriesendorp B, Gauchat-Feiss D, Shi X, Slavcev A, et al. Histoincompatibilities in ABDR-matched unrelated donor recipient combinations. Bone Marrow Transplant (1995) 16(5):641-6.

37. Grundschober C, Rufer N, Sanchez-Mazas A, Madrigal A, Jeannet M, Roosnek E, et al. Molecular characterization of HLA-C incompatibilities in HLA-ABDRmatched unrelated bone marrow donor-recipient pairs. Sequence of two new $\mathrm{CW}$ alleles $\left(\mathrm{Cw}^{\star} 02023\right.$ and $\left.\mathrm{Cw}^{\star} 0707\right)$ and recognition by cytotoxic T lymphocytes. Tissue Antigens (1997) 49(6):612-23. doi:10.1111/j.1399-0039.1997.tb02809.x

38. Sugimoto K, Murata M, Terakura S, Naoe T. CTL clones isolated from an HLA$\mathrm{Cw}$-mismatched bone marrow transplant recipient with acute graft-versus-host disease. J Immunol (2009) 183(9):5991-8. doi:10.4049/jimmunol.0804310

39. Heemskerk MB, Cornelissen JJ, Roelen DL, van Rood JJ, Claas FH, Doxiadis II, et al. Highly diverged MHC class I mismatches are acceptable for haematopoietic stem cell transplantation. Bone Marrow Transplant (2007) 40(3):193-200. doi:10.1038/sj.bmt.1705721

40. Joris MM, van Rood JJ, Roelen DL, Oudshoorn M, Claas FH. A proposed algorithm predictive for cytotoxic $\mathrm{T}$ cell alloreactivity. J Immunol (2012) 188(4):1868-73. doi:10.4049/jimmunol.1102086

41. Joris MM, Lankester AC, von dem Borne PA, Kuball J, Bierings M, Cornelissen JJ, et al. Translating in vitro prediction of cytotoxic $\mathrm{T}$ cell alloreactivity to hematopoietic stem cell transplantation outcome. Transpl Immunol (2014) 30(2-3):59-64. doi:10.1016/j.trim.2013.08.006

42. Tiercy JM, Chapuis B, Gratwohl A, Gmur J, Schanz U, Seger R, et al. Unrelated HSCT: HLA-C disparities result in lower CTLp frequencies and are associated with improved patient survival compared to HLA-AB mismatches. In: Hansen JA, Dupont B editors. Immunobiology of the Human MHC. (Vol. II), Seattle: IHWG Press (2006). p. 605-8.

43. D’Orsogna LJ, Nguyen TH, Claas FH, Witt C, Mifsud NA. Endogenous-peptidedependent alloreactivity: new scientific insights and clinical implications. Tissue Antigens (2013) 81(6):399-407. doi:10.1111/tan.12115

44. Binkowski TA, Marino SR, Joachimiak A. Predicting HLA class I non-permissive amino acid residues substitutions. PLoS One (2012) 7(8):e41710. doi:10.1371/ journal.pone.0041710

45. Thomas R, Apps R, Qi Y, Gao X, Male V, O’HUigin C, et al. HLA-C cell surface expression and control of HIV/AIDS correlate with a variant upstream of HLA-C. Nat Genet (2009) 41(12):1290-4. doi:10.1038/ng.486
46. Apps R, Qi Y, Carlson JM, Chen H, Gao X, Thomas R, et al. Influence of HLA-C expression level on HIV control. Science (2013) 340(6128):87-91. doi:10.1126/science.1232685

47. Kulkarni S, Savan R, Qi Y, Gao X, Yuki Y, Bass SE, et al. Differential microRNA regulation of HLA-C expression and its association with HIV control. Nature (2011) 472(7344):495-8. doi:10.1038/nature09914

48. Kulkarni S, Qi Y, O’HUigin C, Pereyra F, Ramsuran V, McLaren P, et al. Genetic interplay between HLA-C and MIR148A in HIV control and Crohn disease. Proc Natl Acad Sci U S A (2013) 110(51):20705-10. doi:10.1073/pnas. 1312237110

49. Bettens F, Brunet L, Tiercy JM. High-allelic variability in HLA-C mRNA expression: association with HLA-extended haplotypes. Genes Immun (2014) 15(3):176-81. doi:10.1038/gene.2014.1

50. Bettens F, Schanz U, Tiercy JM. Lack of recognition of HLA class I mismatches outside alpha1/alpha2 domains by CD8+ alloreactive T lymphocytes: the HLA-B44 paradigm. Tissue Antigens (2013) 81(6):414-8. doi:10.1111/tan. 12102

Conflict of Interest Statement: The author declares that the research was conducted in the absence of any commercial or financial relationships that could be construed as a potential conflict of interest.

Received: 11 March 2014; paper pending published: 07 April 2014; accepted: 29 April 2014; published online: 19 May 2014.

Citation: Tiercy J-M (2014) HLA-C incompatibilities in allogeneic unrelated hematopoietic stem cell transplantation. Front. Immunol. 5:216. doi: 10.3389/fimmu.2014.00216

This article was submitted to Alloimmunity and Transplantation, a section of the journal Frontiers in Immunology.

Copyright (c) 2014 Tiercy. This is an open-access article distributed under the terms of the Creative Commons Attribution License (CC BY). The use, distribution or reproduction in other forums is permitted, provided the original author(s) or licensor are credited and that the original publication in this journal is cited, in accordance with accepted academic practice. No use, distribution or reproduction is permitted which does not comply with these terms. 